\title{
Les mesures prises dans l'empire de Russie envers les Français soupçonnés de sympathies révolutionnaires (1792-1799)
}

The Measures adopted in the Russian Empire towards the French suspected of having revolutionary sympathies

Julie Ollivier

\section{(2) OpenEdition Journals}

\section{Édition électronique}

URL : https://journals.openedition.org/ahrf/11237

DOI : 10.4000/ahrf.11237

ISSN : 1952-403X

\section{Éditeur :}

Armand Colin, Société des études robespierristes

\section{Édition imprimée}

Date de publication : 1 septembre 2007

Pagination : 105-127

ISSN : 0003-4436

Référence électronique

Julie Ollivier, «Les mesures prises dans l'empire de Russie envers les Français soupçonnés de sympathies révolutionnaires (1792-1799) », Annales historiques de la Révolution française [En ligne], 349 | juillet-septembre 2007, mis en ligne le 01 septembre 2010, consulté le 01 juillet 2021. URL : http://journals.openedition.org/ahrf/11237 ; DOI : https://doi.org/10.4000/ahrf.11237 


\section{LES MESURES PRISES DANS L'EMPIRE DE RUSSIE ENVERS LES FRANÇAIS SOUPÇONNÉS DE SYMPATHIES RÉVOLUTIONNAIRES (1792-1799)'}

Julie OLLIVIER

Dès le commencement de la Révolution Française, Catherine II soutient la cause des princes émigrés, mais ce n'est que dans l'été 1792 qu'elle décide de rompre toutes les relations avec le gouvernement révolutionnaire. La communauté française qui réside en Russie, et qui compte près de 2500 individus, se voit dès lors surveillée et suspectée par le pouvoir russe. Quelques Français sont arrêtés pour avoir trop haut exprimé des opinions révolutionnaires. Le 8 février 1793, un oukase oblige tous les Français à prêter serment de fidélité à la monarchie et à la religion. Cependant les persécutions ne cessent pas, et de nombreuses personnes, dans les années qui suivent, sont expulsées de l'Empire ou déportées en Sibérie pour différents délits. Qu'ils aient prononcé des paroles trop audacieuses en faveur de la Révolution ou contre la Russie, qu'ils aient enfreint les interdictions de se rendre en France ou de communiquer avec leurs relations restées dans ce pays, qu'ils aient tenté de dissimuler leur identité par de faux papiers, ils n'échappent pas à la justice russe. Surtout, trois affaires d'espionnage, dont une seule finalement est fondée, montrent toute la rigueur de la tsarine. Après sa mort en novembre 1796, cette répression se poursuit sous son fils Paul ler, dont la police est particulièrement efficace. Alors qu'il assure un asile au prétendant Louis XVIII à Mitau, qu'il prend à son service l'armée de Condé, et qu'il lance son Empire dans une guerre contre la France dans le cadre de la seconde coalition, la situation des Français résidents en Russie reste très difficile et chaque faux pas peut avoir des conséquences funestes. Ce n'est qu'à l'aube du nouveau siècle, lorsque Paul lor se rapproche de Bonaparte, que la suspicion à l'égard des Français se relâche. Cependant de 1792 à 1799, nombreuses ont été les victimes de ces mesures, qu'elles aient été ou non de véritables sympathisants à la Révolution.

Mots-clés : Russie, répression, expulsion, espionnage, émigration.

(1) Cet article est le fruit de recherches menées dans le cadre d'une thèse sur lcs Français cn Russie sous Catherine II et Paul ${ }^{{ }^{\circ} \text {, }}$, en cotutelle entre l'Université de Bordeaux III sous la direction de $\mathbf{M}$. Figeac, et l'Académie des Sciences de Russie sous la direction de M. Tchoudinov, avec le soutien d'une bourse Lavoisier attribuée par le Ministère des Affaires étrangères français. Je remercie particulièrement M. A. Stroev et M. D. Bovykine pour leurs conseils. 
Dès les premiers jours de la Révolution Française, Catherine II de Russie observe avec méfiance les bouleversements qui se produisent en France ${ }^{2}$. Depuis le début de son règne en 1762 , cette impératrice a cherché à dialoguer avec les philosophes des Lumières comme Voltaire et Diderot, et à donner à son peuple des lois plus libérales, mais elle n'en est pas moins à la tête d'un immense État peuplé de serfs. Elle prend sans hésiter le parti de soutenir la monarchie, et particulièrement les frères de Louis XVI et les émigrés. Cependant les problèmes intérieurs, les guerres constantes menées contre ses voisins, Empire ottoman (1787-1792) et Suède (17881790), les partages successifs de la Pologne (en 1793 et 1795), sont des préoccupations plus pressantes que le rétablissement de la royauté en France. La participation de la Russie se limite à d'importants soutiens financiers en faveur de l'émigration. Paul Irr, monté sur le trône à la mort de sa mère en 1796, continue ces largesses, assure un asile au prétendant Louis XVIII en Courlande et accueille à son service l'armée de Condé. Il va cependant plus loin encore en engageant son Empire dans une intervention militaire contre la France en 1798 dans le cadre de la seconde coalition. L'empereur est toutefois déçu par ses alliés, et Bonaparte incarnant à ses yeux le retour à l'ordre, il change de camp en 1800 et se rapproche de la France.

La communauté française résidante en Russie subit quant à elle les conséquences de cette politique. Ces deux mille cinq cents Français environ, arrivés en grande majorité dans les années 1770-1780, sont étroitement surveillés par le pouvoir russe. Après la rupture totale des relations diplomatiques entre les deux pays en $1792^{3}$, Catherine II décide de prendre diverses mesures contre les Français, fait arrêter les individus considérés comme mal pensants, punit les réfractaires. Sous Paul I ${ }^{c r}$, la répression s'intensifie et touche aussi bien les Russes que tous les étrangers, parmi lesquels les Français restent particulièrement suspects. Dans ces conditions, certains décident de quitter l'Empire, mais la grande majorité reste,

(2) La bibliographie française sur les rapports entre la Russie et la Révolution Française est assez ancienne. L'ouvrage de Charles LARIVIERE, Catherine II et la Révolution française, Paris, Le Sourdier, 1895, fait encore autorité. Dans les dernières publications, voir par exemple le recueil d'articles La Révolution française et la Russie, Moscou, Ed. Progrès, 1989. En revanche, il n'existe aucune recherche sur le thème précis de la répression menée contre les Français en Russie. Les ouvrages généraux ont été amenés à répéter les propos très exagérés du major Masson, Mémoires secrets sur la Russie l...]. Paris, Bertrandet, 18001802, en particulier Léonce Pingaud, Les Français en Russie et les Russes en France, Paris, Perrin, 1886 ou encore Albert LoRThOLARY, Le mirage russe en France au XVIII siècle, Paris, Ed. Contemporaines, 1951. Le major Masson est un témoin fondamental mais partial des événements : originaire de Blamont, près de Montbéliard, Charles François Philibert Masson, se considère comme Suisse. Arrivé en Russie en 1786 pour y rejoindre son frère, il commence une brillante carrière militaire, puis devient précepteur des fils du comte Saltykov, le ministre de la Guerre, et enfin secrétaire du grand-duc Alexandre. C'est donc un homme considéré, proche de la cour et du pouvoir. Pourtant Paul I"r expulse les deux frères pour leurs idées trop dangereuses.

(3) Voir Alfred Rambaud, Recueil des instructions données aux ambassadeurs et ministres de France, tome 9, Paris, Alcan, 1890. 
et la communauté grossit même avec l'arrivée d'émigrés royalistes qui viennent trouver un refuge en Russie. Toutefois aussi bien pour les anciens résidents que pour les nouveaux venus, le moindre faux pas peut être très lourd de conséquences. Sans qu'il soit possible de chiffrer exactement le nombre de Français inquiétés par le gouvernement russe entre 1792 et 1799, il est cependant possible à la lumière des différentes affaires, de distinguer trois délits lourdement condamnés : l'expression d'idées favorables à la Révolution ou contre la Russie, la désobéissance aux lois russes qui interdisent tout contact avec la France, et enfin, le crime le plus grave, l'espionnage 4 .

\section{Le crime de pensée : le sort des Français qui clament trop haut leur sympathie pour la Révolution}

Pendant les deux premières années de Révolution, l'Empire de Russie prône la tolérance à l'égard des Français et des idées libérales. Quelques jeunes nobles russes sont les témoins oculaires des épisodes à rebondissements qui enflamment Paris, et les imprimés circulent librement à Saint-Pétersbourg et à Moscou, faisant avec fidélité le récit des événements. Cependant cette ouverture d'esprit cesse au printemps $1792^{5}$, et les premières mesures réactionnaires se font sentir dans l'Empire. Lécrivain et typographe Nikolaj Novikov, arrêté au mois d'avril pour ses idées subversives et ses activités franc-maçonnes, est condamné à quinze ans de réclusion ${ }^{6}$. Au même moment, et sans qu'il y ait de lien entre ces affaires, les premiers Français Claude Agé et Cuinet D'Orbeil, accusés d'adhérer aux idées révolutionnaires, sont aussi arrêtés et interrogés?

Cette affaire a un retentissement important sur la société en Russie comme en France ${ }^{\beta}$. N'ayant pas de précédent, l'enquête est menée avec

(4) Les documents consultés sont tous conservés dans différentes archives à Moscou et sont tous inédits. N'ont été retenus ici que les dossiers les plus marquants sur une cinquantaine d'affaires, dont certains font plusieurs centaines de pages. Les fonds les plus utilisés sont aux RGADA (Archives gouvernementales russes des actes anciens) : le fonds 7 "Expédition sccrètc " qui correspond aux affaires traitées par la chancellerie secrète ; aux AVPRI (Archives de la politique extéricure de l'empire russe) : les fonds 2 "Collège des Affaires Étrangères" et 6 "Cabinet noir "; aux TslAM (Archives centrales historiques de Moscou) : le fonds 16 "Chancellerie du général gouverneur de Moscou ". Les noms des dossiers ont été traduits en français.

(5) Ni l'arrestation du roi à Varennes en juin 1791, ni l'adoption de la constitution en septembre 1791 n'ont suscité de réaction de la part de Catherine II. Pourtant, en avril 1792, avant même la chute de la monarchie le 10 août, l'impératrice semble prendre conscience du réel danger de la Révolution ct décide des premières mesures répressives.

(6) Novikov, Nikolaj Ivanovic (1744-1818) : homme des Lumières, écrivain, journaliste, éditeur, maçon... Ses multiples activités en faveur du développement social en Russie le font remarquer de Catherine II, qui l'emprisonne. Paul I" le fait libérer en 1796.

(7) RGADA, fonds 7/2, $\mathrm{n}^{\circ}$ 2784. "Sur les Français Agé et d'Orbeil, expulsés des frontières, sur le marchand Mioche et sur Chepor. 1792 ". Ce dossier renferme les trois affaires d'Agé, Cuinet d'Orbeil et Mioche. Les informations suivantes sont extraites de cc dossier, sauf mention complémentairc.

(8) Plusicurs numéros du Moniteur Universel et de la Gazette de France, des mois de mai et juin 1792 se penchent sur cette affaire. Pour une analyse générale de la vision du Moniteur sur la Russie, voir Andrej Mrrrofanov, Julie Olliviek-Chakhnovskala, "Obraz Rossii v presse revolúcionnoj Francii 1789 . $1792 \mathrm{gg}$ " [la vision de la Russie dans la presse révolutionnaire de la France 1789-1792], Evropa : mezdunarodnyj almanah, Tioumen, 2005. 
beaucoup de sérieux par les services de la chancellerie secrète, qui accumulent preuves et interrogatoires. Claude Agé est un prêteur sur gages qui vit dans l'aisance. Son ascension sociale est représentative de la réussite de nombre de ses compatriotes, puisqu'il est arrivé en Russie en 1766 comme perruquier et a ensuite longtemps été précepteur. Il est dénoncé probablement par un compatriote, le gouverncur des pages, qui affirme qu'Agé a prononcé en public « des paroles injurieuses contre les têtes couronnées en disant qu'ils étaient des Tyrans et que les peuples étaient bien sots pour se laisser gouverner par eux, étant des hommes comme eux, et enfin que si on aurait égorgé toute la famille royale et la noblesse d'opposition les affaires auraient été bientôt terminées ". Âgé se défend en prétextant son état d'ébriété et en affirmant que ces propos ne sont pas en accord avec ses idées politiques. Cependant, bien qu'il soit un homme riche depuis longtemps expatrié, il est évident qu'il garde un fort attachement à la France, au petit peuple, et se réjouit des événements révolutionnaires, sans toutefois être assez fou pour tout abandonner et se jeter dans la tourmente. Il a certainement exprimé tout haut ce que de nombreux Français pensent tout bas. Démasqué comme usurier, parasite et jacobin, Claude Agé paie cher son audace en étant immédiatement expulsé de l'Empire.

En même temps que lui et bien que les deux hommes prétendent ne pas se connaître, un autre Français, Cuinet D'Orbeil, est dénoncé pour ses sympathies révolutionnaires. Ce poète s'est installé en Russie vers 1785, en espérant trouver un refuge pour s'exprimer librement. Il connaît d'ailleurs à Saint-Pétersbourg une certaine gloire littéraire, ses vers étant imprimés par l'Académie des Sciences. Pendant trois ans il est employé comme acteur de la cour, puis il assure les fonctions de précepteur et secrétaire particulier chez différentes personnes. En 1792, il est au service du généralprocureur Samojlov" et a ses accès à la cour. Que ce soit pour quelques indiscrétions échappées à Péterhof, dans la résidence d'été de Catherine II $^{w}$, ou à cause d'une dénonciation comme "énergumène ami intime jurécrieur et rédacteur », Cuinet D'Orbeil fait l'objet d'une surveillance attentive. Dans ses papiers, la police trouve plusicurs poésies, lettres et maximes, aussi bien manuscrites qu'imprimées, qui contiennent des propos libéraux, dont une Épitre à l'ombre de Voltaire, qui suscite tout particulièrement les foudres des enquêteurs. L'auteur répond avec franchise qu'il l'a écrit « dans

(9) Samojlov, Aleksandr Nicolaevic (1744-1814) : militaire, il prend part aux deux guerres contre la Porte, et à la paix de lassy. Il est nommé général-procureur en septembre 1792.

(10) Lhistoire de Cuinet D'Orbeil a été racontée par Masson, et sa version a ensuite été reprise par de nombreux historiens. Le poète aurait plaisanté sur l'arrestation de Louis XVI à Varennes. Masson rapporte qu'il fut enlevé de nuit, jeté sur un bateau, et qu'il se précipita à la mer. MAsson, Mémoires secrets, op. cit., tome 2, p. 191-193. Néanmoins les rapports contiennent des lettres de dénonciation. et montrent que le poète est interrogé plusieurs semaines. 
aucune autre intention que pour célébrer l'événement de la destruction de la Bastille qui lui a paru mémorable relativement à tout ce que Voltaire et d'autres auteurs en avoient dit », espérant probablement toucher une impératrice qui a correspondu avec le grand philosophe. Si Cuinet d'Orbeil est décrit par Masson comme " un Français chaud de coeur et d'expression ", il ajoute qu'il est « incapable de rien entreprendre et de rien tramer dont le gouvernement eût pu s'alarmer $»^{\prime \prime}$. D'ailleurs il ne semble pas avoir de contact avec la France, ni fréquenter de cercles compromettants à SaintPétersbourg. Cependant ses idées dérangent, et le 25 avril 1792, Catherine II ordonne de l'expulser sur un navire partant pour la Hollande, où le poète n'arrive jamais.

Le cercle des amis de Cuinet D'Orbeil est aussi mis sous surveillance, ce qui conduit à l'arrestation du marchand Jean-Baptiste Miochc. Depuis son arrivée en 1784 à Saint-Pétersbourg, celui-ci est devenu un commerçant important et respectable, fréquentant la haute noblesse russe ainsi que les gros négociants étrangers de la ville. Ses puissants amis interviennent probablement en sa faveur, car il est relâché rapidement et Catherine II le dédommage en lui accordant des exemptions douanières importantes.

La communauté française en Russie est d'autant plus frappée par ces événements, qu'elle avait jusqu'à cette date été plutôt bien considérée. Le major Masson note que soudain « le nom seul de Français devint une injure ", et que des hommes ayant des places respectables se trouvèrent humiliés et proscrits ${ }^{2}$. En réalité le peuple russe ne s'en prend pas aux Français et il n'y a aucun témoignage de violences, mais les injures viennent de plus haut, de l'administration et de la noblesse. Cependant les ennemis les plus redoutables de la communauté sont les Français eux-mêmes, et avant tout les émigrés royalistes nouvellement arrivés qui manifestent beaucoup de jalousie à l'égard des résidents de longue date et de la réussite de certains.

Limpératrice ne prend de mesure radicale qu'après l'annonce de la nouvelle de la mort de Louis XVI qui est pour elle un véritable choc. Par l'oukase du 8 février $1793^{\prime \prime}$, elle marque son indignation face aux débordements en France. Elle règle les rapports des deux pays, en rompant notam-

(11) Masson, Mémoires, op. cit., tome 2,p. 191.

(12) Masson, Mémoires, op. cit., tome 2, p. 35-37 ; 189-190. Voir aussi Moniteur Universel, $\mathrm{n}^{\circ} 148$, 27 mai 1792. Pour beaucoup de passages publiés dans ce journal, le style et le contenu des informations sur la Russie correspondent exactement aux Mémoires. Nous avons vu en Masson un des correspondants possibles du Moniteur.

(13) Le texte est publié dans tous les journaux européens. Pour une publication récente, voir Dmitri Rostislavelv, Svetlana Tourilovva, "Francuzy v rossii v 1793 godu " [les Français en Russie en 1793], dans Cahiers du monde nusse 39/3, 1998. Cette mesure n'était pas inattendue puisque le Moniteur Universel rapporte neuf mois auparavant à la suite de l'arrestation des trois Français, qu'il est question d' " en faire un dénombrement particulier ». Moniteur Universel, $n^{\circ} 155,3$ juin 1792. 
ment les relations commerciales. Mais surtout la mesure la plus marquante concerne la communauté française, dont les sujets sont invités à partir, sauf s'ils acceptent de prêter un serment de fidélité à la monarchie, soit devant un prêtre, soit devant les autorités du gouvernement local ${ }^{14}$. Les Français doivent s'engager à vivre dans la religion, reconnaître le successeur légitime du trône de France, obéir aux lois de l'Empire russe, et enfin rompre toute relation avec la France, tant que la monarchie n'aura pas été rétablie. Ces promesses ne sont pas à prendre à la légère, puisque les listes des signataires sont publiées, et que ceux-ci sont donc officiellement désignés comme ennemis de la Révolution. Les réfractaires ont trois semaines pour régler leurs affaires, avant d'être expulsés de l'Empire russe.

La mise en place des cérémonies du serment rencontre plusieurs difficulté ${ }^{15}$. La définition même de la nationalité française est une source de conflit et de nombreux Suisses sont obligés de se plier à la loi. L'oukase est appliqué dans l'ensemble des provinces, et la compilation des différentes listes permet d'avoir une évaluation de la communauté française en Russie en 1793, qui s'élève à au moins 2430 individus $^{16}$. Quant aux réfractaires qui quittent la Russie dans les trois semaines, ils sont moins d'une centaine ${ }^{17}$. Dans leur écrasante majorité, les Français ont tout intérêt à se placer sous la protection de Catherine II en acceptant ses conditions. Rien d'ailleurs ne les empêche dans les mois qui suivent de quitter l'Empire, mais les registres de douanes indiquent une très importante baisse des sorties. En effet la communauté se compose d'individus installés depuis plusieurs années, voire plusieurs générations, et dont les enfants sont parfois nés en Russie. Il est vrai qu'ils jouissent souvent de situations matérielles et sociales dont ils n'oseraient pas rêver en France. Ainsi le serment

(14) La formule du serment accompagne le texte de l'oukase, La première phrase est ainsi formulée : * Je soussigné jure devant Dieu Tout-Puissant et sur son Saint Évangile, que n'ayant jamais adhéré de fait ni de volonté aux principes impies et séditieux introduits et professés maintenant en France, je regarde le gouvernement qui s'y est établi comme une usurpation et une violation de toutes les lois, et la mort du Roi Très-Chrétien Louis $X V I$ comme un acte de scélératesse abominable et de trahison infâme ".

(15) Voir AVPRI, fonds 2/1, $n^{\circ} 1293$, "Affaire des Français en Russie, qui ont prêté serment selon l'oukase impérial du 8 février 1793 ", mais aussi TslAM, fonds $16 / 3, n^{\circ} 1$ « Au sujet des Français, qui soutiennent la Révolution française et quittent la Russie. 22.02.1793-21.08.1794 » et TsIAM, fonds 16/1, $\mathrm{n}^{\text {" }}$ 457 « Sur l'expulsion de Russie des Français. 30.01-22.08.1793 n. MAsson, Mémoires secrets, op. cit., tome 2, p. 207-208; tome 3, p. 160.

(16) AVPRl, fonds $2 / 1, \mathrm{n}^{\circ} 1293$. op. cit. Ces listes ont en outre été imprimées en allemand dans plusieurs fascicules, et en russe dans les Sanktpeterburgskie Vedomosti (plus loin Spb-V). Pour l'analyse résumée de ces listes: Vladislav RzEUTSkIJ, "Istocniki po istorii francuzskih zemljacestv v Rossii v sobranii RNB. Spiski francuzov Rossijskoj imperii 1793 g. " [ "Sources sur l'histoire des communautés françaises en Russie dans les collections de la Bibliothèque Nationale de Russie. Les listes des Français de l'Empire russe en 1793 "], Kollekcii. Knigi. Avtografy, n 5, Saint-Pétersbourg, RNB, 2003. Dmitri RostiSL.AVLEV, Svetlana Tourilova, op. cil.. Ces chiffres sont cependant à prendre avec prudence : certaines régions n'envoient pas de rapport ; les personnes qui refusent le serment n'ont pas été comptées ; quelques grands noms de la noblesse française semblent dispensés ; les enfants ne sont pas toujours comptés...

(17) Julie Olitvier-Chakinovskaia, "Les Français expulsés de l'Empire russe par l'oukase de Catherine II du 8 février $1793 »$, Cahiers du monde russe, $n^{\circ}$ 46/3, 2006. 
correspond moins à une question de sensibilité politique face à la Révolution, qu'à un choix matériel objectif. Le major Masson qui se scandalise de cet acte horrible, n'en accomplit pas moins la formalité. En revanche les émigrés se félicitent de cette mesure, comme le comte d'Esterhazy, émissaire officiel des Bourbons à Saint-Pétersbourg, ou encore le marquis de Bombelles ${ }^{18}$. Quant à l'impératrice, elle semble surprise du résultat ${ }^{14}$, mais elle n'est pas dupe, et comprend très bien que certains Français ont fait taire leurs convictions politiques pour des raisons d'intérêts.

Après le départ des quelques réfractaires qui refusent de prêter serment, les Français n'en sont pas moins toujours surveillés de près. Les fervents partisans de la Révolution ne sont pas les seuls suspects, et les Français qui ont une conduite jugée douteuse, ou qui n'ont pas d'activité professionnelle stable, sont tout autant indésirables. L'histoire des aventures du comte de Bellerose ${ }^{2(1)}$ est digne d'un vrai roman, dans lequel le personnage principal joue de malchance. Le 9 avril 1798, un rapport est envoyé de Volhynie à propos d'un Français, qui se nomme le comte de Bellerose. Il est âgé de cinquante ans, invalide, vit de l'aumône des officiers français de l'intendance du prince de Condé ${ }^{21}$ et abuse fréquemment de la boisson. Linterrogatoire révèle que ce militaire français est de ceux qui ont été faits prisonniers par les Russes au siège de Cracovie, et qu'il a été déporté au Kamtchatka pendant vingt ans jusqu'en $1793^{22}$. À sa libération, ne pouvant se rendre en France, il est resté quelques années en Pologne, puis a choisi de revenir en Russie en octobre 1797 . Paul I ${ }^{\text {er }}$ le considère comme un parasite, et puisqu'il est français, il estime qu'il mérite d'être

(18) Valentin Esterhazy, Mémoires, Paris, Plon-Nourrit, 1905, p. 349. Marc-Marie Bombelles, Journal, Paris, Droz, 1998, tome IV 1793-1795, p. 64. Voir aussi AVPRI, fonds 6/2, Bourbons. Esterhazy, Valentin Ladislas comte de (1740-1805) : il arrive le 2 septembre 1791 à Saint-Pétersbourg comme représentant officiel des princes français émigrés, et connaît des succès à la cour de Catherine II, mais il est ćcarté par Paul l". Bombelles, Marc-Marie marquis de (1744-1822) : diplomate, notamment ambassadeur à Venise. Il se rend en janvier 1792 en Russie avec une mission secrète confiée par Louis XVI et son ministre Breteuil, sans que les princes émigrés aient èté avertis de cette démarche. Catherine II refuse ses propositions et en informe Esterbazy et les princes.

(18) RGADA, fonds $5 / 1$ "Correspondances des hautes personnalités avec des particuliers ", $n^{\circ}$ 152. Lettre de Catherine II à Grimm du 13 (24) avril 1793 (localisation indiquée par A. Stroev).

(20) RGADA, fonds $7 / 2, n^{\circ}$ 3137. "Sur la déportation en Sibérie du fêtard français, se nommant lui-mème le comte de Bellerose. 1798 ». Bellerose est libéré le 15 mars 1801 . Il a passé en tout 23 années en déportation.

(21) Paul I'r signe le 27 novembre 1797 l'oukase qui fait rentrer le corps du prince de Condé au service de la Russie. Les troupes françaises stationnent en Volhynie (aujourd'hui en Ukraine). Les officiers français ne cachent pas leur mécontentement, et le pouvoir russe se lasse rapidement de leurs prétentions.

(22) Plusicurs français participent à la guerre entre la Pologne et la Russie (1768-1772) du côté des confédérés, qui se termine en 1772 par le premier partage de la Pologne entre la Russie, la Prusse et l'Autrichc. Une poignée de prisonniers français (probablement une vingtaine) subissent le même sort que les prisonniers russes : ils sont déportés en Sibérie. Par des pressions diplomatiques et l'intervention de quelques hautes personnalités, la plupart sont relâchés dans les années suivantes. 
à nouveau déporté en Sibérie. C'est aussi le sort que connaît en mars 1798 un autre officier français, Kerner, qui a servi dans les armées républicaines au début de la Révolution, ce qui lui est fata ${ }^{23}$.

La déportation en Sibérie, avec toutes ses conséquences souvent funestes, est une sanction fréquente pour éloigner tous les gêneurs et les indésirables. En conséquence, la simple évocation de ces régions inhospitalières suffit parfois à calmer les esprits, du moins c'est ce que semble penser le gouvernement russe qui s'en tient parfois à des menaces. Par exemple le chevalier Pierre Monclar ${ }^{24}$, militaire éprouvé par de nombreuses campagnes, qui erre à travers l'Europe après l'émigration, arrive en Russie en janvier 1798. Il se lie au prince de Sapieha, de vieille noblesse balte, qui lui propose de l'accompagner dans ses domaines. Cette fréquentation ne semble pas du goût de l'empereur, qui ordonne en juin 1798 qu'il soit emprisonné trois jours à Vilnius pour l'effrayer, puis qu'on lui annonce qu'il doit « vivre tranquillement et modestement, sans se permettre aucunement ni de raisonner ni d'écrire sur des affaires qui ne le concernent pas, sinon il sera envoyé en Sibérie pour y résider à perpétuité ». Il est évident que de telles arrestations et menaces perturbent la communauté française, entretiennent des rumeurs et des craintes. Sous Paul $\mathrm{I}^{\mathrm{er}}$, toute allusion, orale, écrite, et même vestimentaire ${ }^{25}$, à la Révolution française, est punie comme un crime.

Si de nombreux Français sont arrêtés pour avoir plus ou moins exprimé des propos favorables à la Révolution, d'autres sont condamnés pour avoir osé critiquer la Russie. En réalité il est difficile de connaître l'opinion réelle des contemporains sur l'Empire, dans la mesure où la poste est ouverte et les voyageurs fréquemment contrôlés, ce qui incite à une très grande prudence dans les correspondances. C'est donc uniquement dans des cas très particuliers, des erreurs ou des étourderies, que les Français dévoilent leurs sentiments. C'est le cas par exemple avec l'officier Dolenoi, émigré en 1791, et agréé dans l'armée russe comme brigadier de la garde à cheva ${ }^{26}$. Il n'a certainement aucune intention d'attirer l'attention sur lui et

(23) RGADA, fonds $7 / 2, n^{\circ}$ 3189. " Sur la déportation du Français Kerner, au service des armées de la République française, à Irkoutsk dans la fabrique de drap. 1798 ». En avril 1802, il implore Alexandre $I^{\text {E' }}$ de lui rendre sa liberté. ment. 1798 ".

(24) RGADA, fonds 7/2, n 3092. "Sur l'étranger Monclar, arrêté pour réflexion sur le gouverne-

(25) Le major Masson et Isabel de Madariaga notent que les pantalons et les chapeaux ronds sont suspects et interdits sous prétexte que les sans-culottes en ont fait leur habit. Isabel de MaDariaGi, La Russie au temps de la Grande Catherine, Paris, Fayard, 1987, p. 611. Masson, Mémoires op. cit., tome 2, p. $35-36 ; 214$.

(26) RGADA, fonds 7/2, $\mathrm{n}^{\circ} 2871$. "Sur l'expulsion hors des frontières du Français Dolenoi pour ses écrits médisants sur la Russie. 1795 ». 
de perdre sa place. Après avoir fait un trajet de Saint-Pétersbourg à Moscou en juin 1795, il se sent souffrant et envoie au maître de police un mot du médecin l'excusant de ne pouvoir présenter dans l'immédiat ses papiers. Cependant il se trompe en expédiant le courrier, et envoie à la place de ce mot, des notes dans lesquelles il raconte son voyage. Victime de son étourderie, Dolenoi joue malgré lui les Radichev français ${ }^{27}$. Il se montre très critique, observant par exemple à propos de la nourriture, que « nous avons été forcé de manger de cette drogue mal pétrie, plus mal cuite encore, à la quelle ces barbares donnent le nom de cléba [pain] ", et décrivant « l'extrême misère de ces sauvages civilisés». À la vue de ces preuves irréfutables de son impertinence et de son ingratitude, Dolenoi est expulsé pour « insulte à la Russie » sur ordre de Catherine II le 9 août 1795.

Si l'on excepte le cas de Dolenoi qui sc dénonce lui-même, les autres affaires montrent dans leur ensemble l'efficacité de la surveillance policière. Chaque parole douteuse finit par être rapportée et toute correspondance est décachetée par le cabinet noir. Après la retentissante affaire des trois Français en 1792 et le serment de fidélité en 1793, la fin du règne de Catherine II est toutefois marquée par une accalmie. Les dénonciations et arrestations ne reprennent qu'à la fin de l'année 1797, soit environ un an après l'avènement de Paul I ${ }^{\text {er }}$, et durent jusqu'à la fin de 1799. Il est ainsi tentant de voir dans cette période de terreur la marque de la politique extérieure de la Russie, puisque ces deux années correspondent à la participation de l'Empire à la deuxième coalition. De manière générale, les affaires sont expédiées plus rapidement sous Paul $\mathrm{I}^{\mathrm{c} r}$, et parfois ne donnent même pas lieu à l'ouverture d'un dossier par la Chancellerie secrète, ce qui interdit toute tentative d'analyse quantitative. En outre l'empereur met en place un véritable service d'espionnage, en particulier à Moscou, débloquant d'importants fonds pour rémunérer des délateurs ${ }^{26}$. Par exemple, le Français Delsol, traducteur de la police, déjeune chaque jour aux frais de l'Expédition secrète, à la table commune des étrangers dans le restaurant de $\mathbf{M}^{\text {me }}$ Chenu, rapportant ensuite les informations entendues. Il ne suffit donc pas aux Français d'avoir prêté serment pour vivre tranquillement en Russie. La communauté est constamment sous surveillance et il semble que personne ne soit à l'abri des accusations. Si pour quelques paroles trop favorables aux idées libérales, il est possible d'être expulsé ou déporté, à plus forte raison la désobéissance aux lois russes est passible de sévères punitions.

(27) Radichev Alexandre Nicolaévitch (1749-1802). Son Voyage de Saint-Pétersbourg à Moscou est interdit dès sa publication en 1790 . Condamné a mort par le tribunal, sa sentence est commuée en dix années de déportation.

(28) TsIAM, fonds 16/3, $n^{\circ} 24$. "Sur la surveillance des étrangers qui habitent à Moscou. 21.04.1798-1.08.1803 ". Ce document contient surtout les dépenses ruineuses de l'opération. 
Le crime administratif : les sanctions à l'égard de ceux qui enfreignent les lois

Les relations diplomatiques entre la France et la Russie sont maintenues durant les premières années de la Révolution, et même si elles sont froides et distantes, la communauté française peut compter sur un soutien officiel pour ses différends administratifs. Après le départ en octobre 1789 du comte de Ségur, les affaires diplomatiques sont confiées à son secrétaire Genet, qui se révèle fervent défenseur du pouvoir révolutionnaire ${ }^{29}$. Catherine II tolère tout au plus sa présence, et après l'arrestation de Louis XVI à Varennes en juin 1791, il lui est ordonné de ne plus paraître à la cour $^{30}$. Genet voit ses prérogatives extrêmement réduites, éprouve même des difficultés à régler les affaires courantes des Français. En juillet 1792, avant même la chute de la monarchie, il reçoit l'ordre de quitter l'Empire ${ }^{31}$. Après son départ, il ne reste plus en Russie comme représentants officiels de la France révolutionnaire que le consul de Saint-Pétersbourg et les viceconsuls de Moscou et de Cronstadt, qui continuent de s'occuper des affaires de la communauté, ce qui ne cesse d'exaspérer le gouvernement ${ }^{32}$. Loukase du 8 février 1793 met fin à leur mission en ordonnant leur expulsion.

Toutefois la rupture des relations diplomatiques ne signifie pas que la communauté française n’a plus aucun représentant en Russie. En réalité il s'opère un changement d'interlocuteurs. Tandis que Genet et les consuls sont mis à l'écart, les émissaires des Bourbons sont reçus à la $\operatorname{cour}^{33}$. Le premier agent de la monarchie à se rendre en Russie est le comte de SaintPriest $^{34}$, qui semble agir par lui-même, et auquel succède rapidement le comte d'Esterhazy qui arrive à Saint-Pétersbourg en septembre 1791. Très bon courtisan, il devient rapidement un intime de Catherine II et de son favori le comte Zoubov ${ }^{35}$, mais ses succès à la cour n'égalent pas ses résultats diplomatiques. Considéré comme le représentant officiel de la

(29) Ségur, Louis-Philippe comte de (1753-1830) : après avoir participé à la guerre d'indépendance américaine, il est nommé, grâce au prestige de son père, ambassadeur en Russie, où il arrive à la fin de 1784. Il y connaît d'importants succès à la fois diplomatiques et personnels. Il décide de rentrer en France en octobre 1789, laissant son poste au chargé d'affaires Genet, Edmont-Charles-Edouard (17621834 ) : frère de Madame Campan, il rentre tót dans la carrière diplomatique. Succédant au comte de Ségur, i) représente le pouvoir révolutionnaire, et est très mal vu à la cour de Russie. Il reçoit l'ordre de quitter l'Empire en juillet 1792.

(30) Ernest DAUDET, Histoire de l'émigration pendant la révolution française, Paris, Hachette, 1906, p. 234. Voir aussi François-Emmanuel SAINT-PRIEST, Mémoires. Règnes de Louis XV et Louis XVI. La Révolution et l'émigration, Paris, Calman-Lévy, 1929. tome 2, p. 114-115.

(31) Charles LARIviérE, Catherine Il et la Révolution française, op. cit. p. 89.

(32) TsIAM, fonds $16 / 1, n^{\circ} 457$. op. cit.

(33) Pour une approche générale, Ernest Daudet, Histoire de l'émigration, op. cit. FrançoisEmmanuel Saint-Priest, op. cit., tome 2. Valentin Esterhazy, Mémoires, op. cit. Marc-Maric Bombelles, op. cir., tome 3.

(34) Saint-Priest, François-Emmanuel Guignard, comte de (1735-1821) : chargé de plusieurs missions en faveur des émigrés auprès de Catherine 11 puis de Paul lir , il essuie à chaque fois des échecs.

(35) Zubov, Platon Aleksandrovic (1767-1822) : dernicr favori de Catherine II à partir de 1789, il multiplie les titres et les fonctions, et prend une part active à la politique étrangère de l'Empire à partir de 1792. 
monarchie française, ses activités sont cependant loin d'être celles d'un ambassadeur. Il se limite à aider les émigrés qui lui sont recommandés, en essayant d'obtenir pour eux des postes ou des pensions. Quant aux simples Français, et surtout ceux qui sont arrivés avant la Révolution, ils n'ont rien à attendre de lui. À partir du départ du chargé d'affaires Genet puis des consuls, ils dépendent uniquement du pouvoir russe.

L'oukase du 8 février 1793 ne se contente pas d'imposer le serment de fidélité, mais il règle aussi l'existence de la communauté, qui jure de vivre sous les lois russes. Il est par exemple défendu aux sujets russes comme aux résidents français de correspondre et de se rendre en France ou dans les pays où se trouvent ses armées. En ce qui concerne la poste, aucune lettre n'est envoyée en France après l'oukase ${ }^{36}$, cependant Constantinople et Copenhague semblent des relais de la correspondance vers Paris. En outre, des missives sont souvent confiées à des voyageurs, échappant ainsi au cabinet noir. Dans la pratique, il est donc possible d'envoyer et de recevoir des nouvelles de France, et cela même après l'oukase du 8 février. Cependant compte tenu des risques et des difficultés, il est évident que ces échanges sont très limités et les exemples de condamnation pour ce délit sont extrêmement rares. Dans l'été 1799, la police découvre des correspondances illicites chez trois Français, qui sont déportés en Sibérie $^{37}$, bien que le contenu des écrits incriminés soit purement personnel.

Une autre loi, particulièrement contraignante, concerne les passeports. D'après l'oukase du 8 février, tous ceux qui désirent pénétrer dans l'Empire, doivent être munis d'" un certificat des Princes français, et nommément du Comte de Provence et du Comte d'Artois frères du feu Roi, ainsi que du Prince de Condé, et après avoir, par l'entremise de NOS Ministres les plus proches du lieu de leur séjour, sollicité auparavant NOTRE permission de venir en Russie ", ce qui revient à obtenir deux passeports, l'un des princes émigrés, l'autre d'un ambassadeur russe. Ces précautions interdisent la venue de Français non royalistes, et de tous ceux qui n'ont pas un objectif précis en Russie, ce qui explique pourquoi après 1793 presque tous les nouveaux arrivants sont des émigrés qui s'engagent dans l'armée impériale. Quant à ceux qui ne bénéficient pas de ces titres et cherchent malgré tout à entrer dans l'Empire, ils sont parfois tentés de falsifier leurs documents. Contrefaire les attestations données par les princes étant bien trop difficile, la solution la plus simple est en fait de contourner la loi, en se réclamant d'une autre nationalité et en rédigeant les attestations habituelles requises pour les étrangers. Il est bien entendu

(36) AVPRI, fonds 6/2, Bourbons, 1790-1799.

(37) RGADA, fonds $7 / 2, n^{\circ} 3395$ " Sur la déportation à Nerchinsk des Français Charles Perrin et Joseph Martin, soupçonnés de mal penser. 1799 ", et $n^{\circ} 3319$ « Sur le marchand français Rennau, suspecté de mal penser, envoyé vivre à Irkoutsk. 1799 n. 
impossible d'évaluer le nombre de Français qui ont usé de ce stratagème, car seuls sont connus ceux qui ont été arrêtés.

Le cas de Dubrou ${ }^{3 *}$, parce qu'il est le premier, est le plus retentissant et porteur de conséquences. Ce Français arrive à Saint-Pétersbourg en avril 1794, prétendant vouloir soit s'engager dans l'arméc, soit comme précepteur. Il n'a pas de connaissances en Russie, tout au plus quelques lettres qui doivent lui servir de recommandations. Dès son arrivée, il rencontre Philippe Sénac de Meilhan ${ }^{39}$, auquel il confie ses mésaventures, et avoue qu'il est entré en Russie avec de faux passeports suisses. Le dossier de la chancellerie secrète n'indique pas de quelle façon Dubrou est arrêté trois jours plus tard, mais il n'est pas exclu qu'il se soit lui-même rendu à la police afin de régulariser sa situation. Il est emprisonné quelques jours, tandis que les Français qu'il a fréquentés sont invités à témoigner. Finalement c'est une lettre de Dubrou adressée de Copenhague en août 1794 qui apporte des éclaircissements sur la suite de cette affaire ${ }^{4(1)}$. Dubrou exagère certainement ses malheurs, écrivant qu'« on me conduit en prison [...]. Huit jours après on me conduit à Cronstadt, où après un mois du plus cruel tourment et de séjour le plus affreux, je suis jeté sur un bâtiment. La mer me vomit à Copenhague ». Il est pourtant dans l'intention de revenir en Russie, pour laver soi-disant son honneur, et affirme avoir obtenu du comte d'Artois et de l'ambassadeur Rumjancev de vrais passeports ${ }^{41}$. La conduite de Dubrou est pour le moins étrange, si l'on considère premièrement qu'il avait dès le début la possibilité d'obtenir les documents nécessaires pour être en règle, deuxièmement qu'il s'est adressé à des compatriotes ayant mauvaise réputation, et non au comte d'Esterhazy comme les autres émigrés, et surtout, troisièmement, qu'il souhaite revenir dans un pays où il a été maltraité et où rien ne lui est promis. À la suite de cette affaire, la police redouble de vigilance, comme en témoigne un voyageur français qui arrive un mois plus tard, muni d'un faux passeport italien, et qui reçoit à son auberge la visite de deux officiers venus vérifier sa connaissance de la langue italienne, par « précaution par rapport d'un Français, qui était venu avec un passeport suisse ${ }^{42}$. La situation est donc particulièrement tendue pour tous les étrangers en 1794 mais il semble que cette sévérité s'atténue dans les années qui suivent, comme le montre l'affaire de Madame Michel.

(38) RGADA, fonds $7 / 2, n^{\circ} 2827$. "Sur l'arrivée à Saint-Pétersbourg du Français Debrou [sic], qui avait un passeport falsifié. 1794 m.

(39) Il s'agit du fils de Gabriel Sénac de Meilhan, resté en Russie après le départ de son père en 1791.

(40) AVPRI, fonds 6/2, Bourbons. 1794. partie 4. Lettre de M. Dubrou à M. Maillian, de Copenhague, du 16 auût 1794 (sous couvert du marchand La Rose).

(41) Rumjancev, Nikolaj Petrovic (1754-1826) : ambassadeur à Francfort sur le Main, Catherine II le nomme en 179 I son attaché auprès de la cour des Bourbons en exil, comme Esterhazy représente les Princes à Saint-Pétersbourg.

(42) RGADA, fonds $7 / 2, \mathrm{n}^{\circ} 2843$. " Sur le Français Lamanon, arrivé à Saint-Pétersbourg avec un faux passeport, soupçonné d'espionnage, et enfermé dans la forteresse. 1794 ». 
La Française Thérèse Michel est coupable à la fois d'être rentrée en Russie sans passeport, mais aussi d'être allée en France ${ }^{4.3}$. En décembre 1797, son mari François Michel est expulsé de Russie ${ }^{44}$, mais elle-même ne part que l'été suivant. Son retour à Moscou en août 1799, après une absence de presque un an, éveille les soupçons du maître de police. Le récit qu'elle fait de son voyage est édifiant, car elle a traversé toute l'Europe, a séjourné trois mois à Paris, puis, de là, elle a fait la route inverse en pénétrant dans l'Empire russe par Kiev. Elle est restée un mois à Moscou, puis un autre mois à Saint-Pétersbourg, et enfin elle est revenue à Moscou. $\mathrm{Au}$ cours de ce voyage, le seul passeport qu'elle a utilisé est celui pour sortir de Russic, puis aucun document ne lui a plus été demandé ! Elle connaît certainement les astuces pour passer sans problème les douanes, la corruption n'étant pas exclue. Ce n'est d'ailleurs probablement pas un hasard si elle passe par Kiev, qui n'est pas la route la plus directe de Paris à Moscou. Thérèse Michel et son père Jacques Brochar, à qui elle a écrit de France, sont expulsés. Comme cette affaire a prouvé que les frontières de l'Empire sont perméables, l'empereur rappelle le 23 septembre 1799 à tous les gouverneurs civils qu'il est formellement interdit de laisser entrer en Russie les étrangers qui ne peuvent présenter un passeport du Collège des Affaires étrangères donné par un ambassadeur ${ }^{45}$.

La circulation des marchandises, tout comme les allers et retours des personnes, est strictement contrôlée par les douanes et la police $^{4 \hbar}$. L'oukase du 8 février 1793 interdit le commerce direct entre la France et la Russie, et, de fait, met un terme au traité signé en janvier 1787. Mais les échanges étant essentiellement entre les mains des Anglais et des Hollandais, c'est plus l'oukase du 8 avril 1793, soit deux mois plus tard, qui porte le véritable coup en interdisant toute importation de marchandises françaises en Russie ${ }^{47}$. Sous Paul I ${ }^{\text {er }}$, cette loi connaît différents aménagements, et en particulier les alcools français sont pour un temps autorisés à nouveau ${ }^{48}$. La police et les douanes contrôlent scrupuleusement les marchandises importées et les commerçants, d'autant plus suspectés que leurs déplacements

(43) TsIAM, fonds 16/1, $\mathrm{n}^{\circ}$ 1107. «Sur l'arrivée à Moscou de la Française Thérèse Michel. $15 / 26.09 .1799$ "

(44) TSIAM, fonds 16/1, $\mathrm{n}^{\circ}$ 730. “ Sur l'expulsion hors des frontières du Français Michel el de madame Defarge. 20.10-7.12.1797 ", et $n^{\circ}$ 736. "Sur l'interdiction de rentrer à Moscou pour les Français qui possèdent un passeport ancien. 29.10-20,11.1797»

(45) TsIAM, fonds $16 / 225, n^{\circ} 214$. "Sur la sortic hors des frontières de la Française Michel. 23.09.1799-4.10.1799"

(46) Sur le commerce du vin français en Russie, notamment pendant la période révolutionnaire, voir Julie Oluvier-ChakhinovskaiA, "Le vin français sur les tables russes, à l'époque de Catherine II et Paul ler ", à paraître dans le cadre de la publication des actes du colloque Cervin, Bordeaux, mai 2005.

(47) Sph-V $\mathrm{n}^{\circ}$ 40, 20 mai 1793. Cet oukase fait grand bruit en Europe et désole les Français Moniteur Universel, $\mathrm{n}^{\circ} 150,30$ mai $1793 ; \mathrm{n}^{\circ} 352,8$ septembre 1794. Voir aussi Antoine ANTHOINE, Essai historique sur le commerce et la navigation de la Mer-Noire /...J, Paris, H. Agasse, an XVIII (1805), p. 241-242.

(48) $S p b-V, n^{\circ} 9,30$ janvier 1797. Oukase du 16 janvier 1797. 
peuvent couvrir facilement des activités d'espionnage. La famille Plus par exemple est particulièrement surveillée ${ }^{49}$ : Jean Plus, marchand français de Moscou, est expulsé en automne 1797 après son retour de Hollande. Ses fils, Jean et Nicolas, étant restés dans l'Empire, chacun de leurs déplacements fait l'objet de rapports, jusqu'à ce qu'ils demandent eux-mêmes à quitter définitivement le pays en avril 1800, lassés de cette constante pression. D'autres marchands sont tracassés pour la provenance de leurs marchandises, particulièrement en 1799 et 1800 , et malgré les preuves fournies que ces articles ne sont pas importés de France, ils sont parfois lourdement condamnés ${ }^{51}$. Compte tenu de la surveillance efficace et de l'absence de fraudes réelles constatées, il est possible de conclure que les marchandises françaises ne pénètrent pas en Russie durant cette période, hormis celles autorisées par l'empereur.

\section{Le crime d'espionnage : les agents français, présumés ou avérés}

Parmi les Français arrêtés pour avoir prononcé quelques paroles favorables à la Révolution ou bien pour n'avoir pas obéi aux lois russes, se trouvent peut-être quelques espions. Les déplacements de Madame Michel en Europe et en Russie sans la moindre autorisation, ou encore les tentatives de Dubrou pour pénétrer dans l'Empire avec de faux passeports, sont pour le moins suspects, même s'ils n'ont pas été accusés d'espionnage ${ }^{5 !}$.

(49) TsIAM, fonds $16 / 225, n^{\circ}$ 39. « Affaire de la collecte d'informations sur le Français Plus ». De même fonds $16 / 1, n^{\circ} 963$. "Sur l'autorisation de donner un passeport pour l'étranger à l'officier de marine royale française Rospic 17.01-31.08.1799. ». La majorité des rapports concernent l'affaire de Jean et Nicolas Plus. Voir aussi RGADA, fonds $7 / 2, n^{\circ} 3296$ " Sur le sujet russe et marchand français Plus. 1799 \#.

(50) TsIAM, fonds $16 / 1, n^{\circ} 1117$. "Sur les relations commerciales du marchand français Louis Menionier. 26.09.1799 . TsIAM, fonds $16 / 3, \mathrm{n}^{\circ} 46$ « Sur l'interdiction de vendre des marchandises françajses à Moscou. 22.12.1799-27.06.1802 " et RGADA, fonds 7/2, $\mathrm{n}^{\circ} 3418$ "Sur la déportation en Sibérie de Moscou des marchands étrangers Magnian, Bekkers et Montan. $1800 \mathrm{~m}$.

(51) Il n'existe aucune recherche sur l'espionnage français en Russie pour la période de la Révolution. Les travaux d'Alexandre Stroev sont essentiellement consacrés aux agents de Louis XV en Russie lors de la première guerre avec la Porte. Aleksandr STROEv, "Vojna perev : francuzskie spiony v Rossii vo vtoroj polovine XVIIl veka " fla guerre des plumes : les espions français en Russie dans la deuxième moitié du XVIII' siècle], Logos 3 (24), Moscou, 2000. Aleksandr STrokv, "Les espions français en Russie durant la guerre entre la Russie et la Turquie (1768-1774) ", sous la dir. de Jean-Pierre Poussou, Anne Mezin, Yves Perret-Gentil, L'influence française en Russie au XVIII siècle, Institut d'Études Slaves et Presses Universitaires de Paris-Sorbonne, Paris, 2004. Il faut aussi signaler les analyses d'Aleksandr Tchoudinov sur Gilbert Romme. Aleksandr Tchoudinov, " Gilhert Romme à propos de l'armée russe au XVIII" siècle ", Cahiers du monde nusse, 40/4, 1999. Gilbert Romme, précepteur du jeune comte Stroganov, est

l'auteur

d'“ Observations sur le Militaire de Russie en 1780 \# rédigées lors de son séjour en Russie de 1779 à 1786. Les dépêches de Genet éditées par Alfred RAmBaud, op. cit., p. 530, évoquent deux étrangers servant dans l'armée russe, Lusk et l'anglais d'origine française Chateauneuf, que le chargé d'affaires a recruté comme espions. Cependant dans la perspective de cet article, ce n'est pas tant l'identité des vrais espions, ni les renseignements qu'ils ont pu fournir à la France qui suscitent ici l'intérêt, que l'étude des affaires des Français arrêtés pour espionnage présumé ou avéré. 
Le premier Français accusé d'espionnage est Jean Alexandre Bonneau au mois d'avril $1793^{52}$. Les conditions de son arrestation ne sont pas secrètes, puisque plusieurs contemporains en ont connaissance. Résidant en Pologne depuis plus de vingt ans, et marié à unc polonaise, Bonneau a servi plusieurs années le Ministère des Affaires étrangères, comme correspondant particulier . Il poursuit cette activité pour le compte du gouvernement révolutionnaire, prétextant que ce revenu fait vivre sa famille. Au début de l'année 1793, il est plus ou moins chargé des affaires de France à Varsovie après le départ du représentant officiel le marquis Descorches de Sainte-Croix. Sur les ordres de l'ambassadeur russe en Pologne, le comte Jakov Sivers ${ }^{53}$, il est arrêté le 13 mars 1793 et envoyé sous escorte à Saint-Pétersbourg. Dans ses papiers sont saisis les originaux de dépêches adressées au Ministère français, ainsi qu'un chiffre amovible.

Bonneau est conduit à la forteresse Pierre et Paul, où il est interrogé pendant deux mois. Le crime qui lui est reproché est clair : «La légation de France ayant cessé en Pologne, Bonneau qui y était attaché, devait se retirer pareillement de ce pays : mais comme il y est resté, en continuant sa correspondance illicite, il doit subir la punition d'espion, dans toute sa rigueur ». Pour se défendre, l'accusé choisit la franchise, affirmant qu'il a toujours servi comme simple correspondant, activité qu'il n'a jamais cachée, et qui a toujours été tolérée par le gouvernement polonais. Le dossier d'accusation contient onze dépêches pour l'année 1792, et onze autres pour 1793 jusqu'au 9 mars, qui ne comportent rien d'autre qu'une description des événements politiques de la Pologne. Ni les dépêches, ni les interrogatoires ne permettent de connaître les sentiments de Bonneau à l'égard de la Révolution ou du partage de la Pologne. Cependant il est accusé de dissimuler la vérité, et un rapport indique qu'il " se trompe furieusement puisqu'il ne sortira jamais de la prison sans qu'on ne soit pas content de lui et de ses confessions ». Ses révélations n'étant pas à la hauteur des espérances du pouvoir russe, il est rapidement délaissé, les interrogatoires cessent, aucun jugement ne décide de son sort. Après trois années de détention, il n'a cependant pas perdu tout espoir de prouver son innocence. Lorsque Paul $\mathrm{I}^{\mathrm{er}}$ monte sur le trône en novembre 1796 , il le supplie de décider enfin de son sort. Sa femme, devenue sujette du roi de Prusse Frédéric-Guillaume II par le troisième partage de la Pologne en octobre 1795, réclame la protection de son nouveau souverain dans cette affaire. Lambassadeur de Prusse à Saint-Pétersbourg obtient ainsi sa liberté à la fin du mois de novembre 1796. L'empereur n'a bien entendu

(52) RGADA, fonds $7 / 2, n^{\circ} 2808$. « Sur l'agent du gouvernement français Jean Bonneau, amenć de Pologne à la forteresse. 1793-1796\%.

(53) Sivers Jakuv-loann Efimovic, comte (1731-1808) : De 1789 à 1794, il est ambassadeur de Russie en Pologne et contribue au deuxième partage du pays (1793). 
pas relâché Bonneau par mansuétude, mais pour faire un geste agréable à la Prusse.

La seconde affaire d'espionnage a aussi une dimension européenne, mais dans la mesure où le comte de Montagut-Barrau appartient à la noblesse émigrée, et où il reconnaît être coupable des crimes qui lui sont imputés, l'affaire a beaucoup plus d'ampleur ${ }^{54}$. Au moment des premières secousses de la Révolution, cet officier de la marine royale se trouve en Orient avec le grade de lieutenant. Il séjourne plusieurs mois à Constantinople, puis se détermine à rejoindre les princes émigrés à Coblence dans l'automne 1792. À Vienne, par l'intermédiaire du prince de Ligne, il rencontre l'abbé Sabatier ${ }^{5 s}$, qui lui propose une mission secrète. Selon ses dires, c'est par manque d'argent qu'il accepte cette offre déshonorante, les sommes promises étant particulièrement séduisantes. Il doit dans un premier temps se rendre à Iassy, pour transmettre un mémoire au prince de Moldavie ${ }^{\text {st }}$ et se placer sous ses ordres. Pour le cas où le prince l'enverrait en Russie, Sabatier lui donne pour instruction « de prendre en détails le plan des portes des arsenaux, et d'envoyer l'état des vaisseaux et des armements qui pourraient se faire. Je devais pour cela passer par Kherson, Nicolaev, Sébastopol ${ }^{57}$; et me rendre le plus tôt possible à SaintPétersbourg, où je devais tâcher de deviner les secrets ». Montagut arrive à Iassy au début du mois de février 1793, et rencontre Moruzi, qui protège un certain nombre de Français jacobins et propose en effet à Montagut d'aller à Saint-Pétersbourg pour lui fournir des renseignements.

Muni d'un passeport en règle, et de lettres de recommandations, Montagut arrive à Saint-Pétersbourg en mars 1793, alors que le comte d'Artois est l'invité de Catherine II. N'y trouvant pas l'argent promis par Moruzi, il essaie sans succès d'être pris dans la suite du prince français, puis demande à entrer au service de la Russic, comme beaucoup de compatriotes émigrés, écrivant au favori Zoubov que c'est pour cette raison qu'il est venu en Russie, sur les conseils du prince de Nassau ${ }^{58}$. Reçu en avril 1793 comme capitaine lieutenant dans la flotte de la Mer Noire, il semble déçu

(54) RGADA, fonds 7/2, $\mathrm{n}^{\circ}$ 2817. "Sur le capitainc-lieutenant Montagut, inculpé d'espionnage, sur le Français Girard, l'ayant dénoncé, et sur son serviteur le polonais Trohnitskoj. 1794 ". Les faits et documents cités sur cette affaire sont tous issus de ce dossier, sauf mention d'une source différente.

(55) Ligne, Charles-Joseph, prince de (1735-1814) : né à Bruxelles, sa carrière militairc et mondaine se joue dans toutes les cours d'Europe. Il se rend notamment deux fois en Russie et correspond activement avec Catherine Il. Sabatier de Castres, Antoine (1742-1817) : surtout célèbre comme écrivain, notamment par son Dictionnaire de Littérature. Favorable à la Révolution à ses débuts, il émigre rapidement à la fin de l'annéc 1789 .

(56) Moruzi Alexandru (1750-1807) : voïvode ou hospodar de Moldavie et de Valachic. Prince visionnaire et aventurier, franc-maçon. Il est protégé par la Russic.

(57) Kherson, Nikolaev et Sevastopol' sont trois ports de la mer Noirc fondés sous Catherine II.

(58) RGADA, fonds 193, $n^{\circ} 715$. "Montagut ". Nassau-Siegen, Charles-Henri-Nicolas-Othon, prince de (1745-?) : aventurier, militaire. Il entre dans la marine russe en 1788 avec l'autorisation de Louis XVI. Se distinguant dans les guerres contre la Porte ct contre la Suède, il pénètre le cercle intime de Catherine II. En 1791, il apporte son aide à l'armée des princes émigrés. 
par ce grade, gagné qu'il est par l'inquiétude et le remords. C'est alors qu'il confie tous ses malheurs à un compatriote, un certain M. Gérard, qui n'a pas ses scrupules, et lui propose de le remplacer comme agent de Sabatier et Moruzi. Montagut accepte et écrit en mai 1793 une lettre au prince Moruzi, ainsi qu'un mot de recommandation pour Gérard, qui quitte SaintPétersbourg dans l'intention de se rendre à Iassy. Montagut va quant à lui prendre son service et pendant une année rien ne semble transparaître de ses anciennes activités. Mais en juin 1794, il est trahi par Gérard, arrêté et conduit à Saint-Pétersbourg. En réalité Gérard n'est jamais allé en Moldavie : lorsqu'il a fait sa demande de passeport, il s'est vu proposer un emploi dans l'administration russe, ce dont il rêvait depuis longtemps. Cependant ce n'est qu'un an plus tard, qu'il dénonce toute l'affaire, cherchant certainement à prouver sa reconnaissance et sa fidélité au gouvernement russe.

Montagut est interrogé à maintes reprises en prison, surtout sur Sabatier, Moruzi et leurs plans. II reconnaît sa culpabilité, mais cherche à atténuer son crime : il ne s'est pas fait de relations, le seul arsenal qu'il a visité est celui de Kherson après avoir renoncé à sa mission, et il n'a jamais envoyé de lettre, passant sous silence celle transmise au prince Moruzi par l'intermédiaire de Gérard, signée du nom convenu «D'ezon », mais qui, à vrai dire, ne donne que quelques nouvelles militaires sans intérêt. Dans toutes ses réponses, il témoigne d'idées bien arrêtées sur la noblesse, l'honneur et la religion, qui plaident en sa faveur. Après avoir été jugé, Montagut est reconnu coupable d'espionnage sur ses propres aveux, par oukase impérial daté du 18 décembre 1794. La peine de mort ordinairement réservée aux espions, est commuée en travaux forcés et déportation à vie en Sibérie, par égard pour sa naissance noble.

Enfin la troisième affaire d'espionnage est tout aussi rocambolesque, même si elle n'a pas la même résonance que celle de Montagut. Presque à la même date que ce dernier, à la fin du mois de mai 1794, un homme, cheminant à pied sur la route de Saint-Pétersbourg, est arrêté ${ }^{5 \%}$. Il porte un passeport italien au nom de Rosolini, et a dans sa malle de très nombreux papiers concernant la Révolution Française. Il est conduit dans la capitale et emprisonné à la forteresse Pierre ct Paul.

Linculpé est Pierre Paul de Lamanon d'Albe, ancien chanoine d'Aix. Nommé électeur en 1789 , il a, entre autres, reçu les honneurs d'une séance de la Convention nationale et côtoyé Robespierre. Il a lui-même rédigé un ouvrage manuscrit sur ses activités révolutionnaires, intitulé Vrai point de vue, sous lequel on doit considérer la révolution de France, auquel on a joint quelques anecdotes intéressantes et curieuses de la vie de l'auteur et qui ont

(59) RGADA, fonds 7/2, $n^{\circ}$ 2843. « Sur le Français Lamanon, arrivé à Saint-Pétersbourg avec un faux passeport, soupçonné d'espionnage et enfermé dans la forteresse. 1794 ». 
rapport à la révolution, depuis le mois d'avril 1789, jusqu'au 16 octobre 1793. Lamanon ne cache pas qu'il a été favorable à la Révolution à ses débuts, mais prétend s'être ensuite dressé contre la Terreur, cette opposition lui ayant valu une condamnation à la guillotine, à laquelle il a échappé en s'évadant de prison en octobre 1793. Il a ensuite émigré en Suisse, puis à Copenhague, où il a fréquenté quelques jacobins. De là, il a formé le projet d'aller en Russie, afin de présenter une montgolfière à l'impératrice, et pensant qu'en cas d'échec, il pourrait aisément trouver une place de précepteur. Muni de passeports italiens pour éviter tout désagrément, il arrive donc à Saint-Pétersbourg à la mi-mai 1794. Cependant en apprenant les mésaventures de Dubrou qui a cherché à se faire passer pour Suisse, il est pris d'une réelle terreur et décide de fuir au plus vite.

Bien que tous les détails donnés par Lamanon paraissent extravagants et très exagérés, la chancellerie secrète prend cette affaire au sérieux. Ce n'est pas tant le subterfuge des passeports qui intéresse la police, que le passé révolutionnaire de Lamanon et ses fréquentations jacobines à Copenhague. Le ministre de Russie au Danemark, le baron Krudener, confirme qu'on considère Lamanon « comme un émissaire de la Convention sous le masque d'un aristocrate ". Il est ainsi accusé d'espionnage, même s'il ne reconnaît pas les faits qui lui sont reprochés, et qu'en définitive aucune preuve formelle n'appuie cette assertion. Lamanon cherche à se disculper par le récit de ses malheurs, mais il convient lui-même que toutes ses explications sont « peu conformes à la saine raison ». En effet son esprit semble un peu dérangé, et en décembre 1794, le commandant de la forteresse confirme qu'il est fou. Dans ces circonstances, il ne peut être ni jugé, ni expulsé, et reste en détention plusieurs années. Placé dans une maison de fous en avril 1798, il meurt à peine quelques jours plus tard.

Ces trois dossiers datés de 1793 et 1794 sont les seuls pour la période révolutionnaire qui portent l'accusation d'espionnage. À première vue ils ont peu de similitudes, puisque seul Montagut reconnaît les faits dont il est accusé, tandis que les deux autres suspects nient toute activité secrète. Bonneau a bien sûr donné des informations au Ministère français, mais sans se cacher, et sans chercher à percer les secrets de la politique russe en Pologne. Quant à Lamanon, rien dans ses papiers ne témoigne de relations avec la France. C'est d'ailleurs l'absence de preuves et d'aveux qui décide le pouvoir russe à ne juger ni Bonneau ni Lamanon. En ce qui concerne les idées politiques, seul Lamanon a réellement participé à la Révolution et son émigration très tardive ne l'empêche pas d'éprouver de nettes sympathies à son égard, tandis que Bonneau semble y être indifférent, et Montagut se comporte comme un émigré royaliste.

Malgré ces différences fondamentales, les trois affaires ont un point commun très intéressant : leur dimension internationale. Ces agents ne sont pas accusés d'espionner pour le gouvernement révolutionnaire fran- 
çais, et d'ailleurs leurs relations avec leur patrie intéressent peu la chancellerie secrète. Il faut ainsi replacer l'arrestation de Bonneau dans le cadre du deuxième partage de la Pologne effectué en janvier 1793. Varsovie se trouvant en territoire russe, les Français doivent, comme dans l'Empire, respecter en tous points l'oukase du 8 février. Bonneau est donc coupable d'avoir continué à entretenir des liens avec la France par sa correspondance politique et sa désobéissance est assimilée au crime d'espionnage. L'histoire de Montagut révèle plus encore l'existence de réseaux internationaux d'espionnage, qui se tissent moins pour la France que contre la Russie. Le premier commanditaire de Montagut est Sabatier, émigré français à Vienne, pour lequel la chancellerie secrète cherche à cerner l'étendue de ses liens avec la Pologne, la Suède et la Porte, les trois ennemis de la Russie. Il est plus étonnant que derrière Sabatier se dresse l'hospodar de Moldavie et de Valachie ${ }^{60}$. Ces régions très convoitées, disputées à l'Empire ottoman aussi bien par l'Autriche que par la Russie, sont, en 1793, épuisées par les guerres et les luttes intestines ${ }^{\prime \prime}$. Moruzi cherche à se renseigner sur la Russie, et en particulier sur son état militaire, le choix d'un émigré noble français pour cette mission n'étant pas fortuit. Gérard dénonce ce projet comme une « intrigue pour la porte ottomane et les rebelles polonais, en partie dirigé par le prince Morasi hospodar de Valachie ». Cependant les réponses de Montagut sont décevantes : qu'il dise la vérité ou dissimule, il avoue ne rien connaître à la haute diplomatie internationale. Enfin l'affaire de Lamanon a aussi une dimension européenne : si son passage en Suisse ne suscite pas la curiosité des enquêteurs, en revanche son séjour au Danemark les intéresse au plus haut point, d'autant plus que, dans ses papiers, se trouvent de nombreuses lettres de Français jacobins résidant à Copenhague. Il est vrai que la cour du Danemark regarde d'un oil amusé les événements de France, et qu'elle n'a pas fait de difficultés en accueillant en août 1793 le nouveau ministre plénipotentiaire de la Convention, Philippe Antoine Grouvelle ${ }^{62}$. La Russie observe attentivement la situation

(60) Sabatier s'explique lui-même sur ses rapports avec Alexandru Moruzi, dans SABATIER DE CASTRES, Lettres critiques, morales et politiques sur l'esprit, les erreurs et les travers de notre temps, Erfurt, Hennings, 1802 (source indiquéé par M. Stroev). Il est de ces émigrés qui cherchent à jouer le rôle d'intermédiaire entre les cours européennes.

(61) Ces territoires sont occupés par les Russes pendant la première guerre contre la Porte (1769 à 1774) et la seconde (1788-1792). Aleksandr StROEv, Ilcana MiHAlLı (I.), Énger une République souveraine, libre et indépendante. Mémoires de Charles-Léopold Andreu de Bilistein sur la Moldavie et la Valachie au XVIII siecle, Bucarest, Roza Vânturilor, 2001. Lors de la première guerre, plusieurs agents français en Moldavie tentent d'organiser un soulèvement au profit des Turcs. Aleksandr STROEV, "Les espions français $\mathrm{cn}$ Russic |... " ", op. cit. Voir aussi Nicolae IorGA, Histoire des relations entre la France et les Roumains, Iassy, Ed. Progresul, 1917.

(62) Philippe Antoine Grouvelle (1757-1806). Ce poète et protégé de la cour de France se rallie aux idées révolutionnaires. Secrétaire du Pouvoir exécutif, il est notamment chargé le 20 janvier 1793 de lire à Louis XVI sa sentence de mort. Craignant la réaction et ne pouvant émigrer, il parvient à quitter Paris en se faisant nommer en mai 1793 ministre plénipotentiaire au Danemark. 
politique au Danemark et les éventuels rapprochements avec la France révolutionnaire. Entourée de puissances rivales et de nations outragées, elle semble avoir plus à s'inquiéter d'espions au service de ses voisins que d'agents envoyés par le gouvernement révolutionnaire. Les Français qui errent sur les routes d'Europe pendant la période révolutionnaire sont pris dans un tourbillon d'intérêts politiques qui les dépasse.

La chancellerie secrète n'use jamais de mauvais traitements. Les accusés sont interrogés à plusieurs reprises à l'écrit, et répondent euxmêmes par des mémoires en français, ayant tout le papier nécessaire pour expliquer leur version des faits. Cependant les conditions de détention sont dures et Bonneau se plaint de l'absence d'hygiène, de la vermine, de la promiscuité, du dénuement matériel, mais il résiste malgré tout à trois années d'emprisonnement. Pour écourter leur détention, les enquêteurs incitent les accusés à avouer la vérité pour être plus vite jugés et inspirer la clémence de Catherine II. Ainsi les trois détenus semblent tous répondre avec franchise aux interrogatoires, mais cette apparence peut être trompeuse. En ce qui concerne Montagut, il a uniquement reconnu les crimes dont il était inculpé par le gouvernement russe, et a pu dissimuler une partie de ses activités, comme le montre une lettre du comte d'Antraigues à l'ambassadeur russe à Venise, Mordvinov, en janvier $1795^{63}$. Par l'intermédiaire de Besnard, un des gardes des archives du Comité, il a pu savoir qu'« il y a eu des intelligences directes entre le Comité du temps de Robespierre et un français au service de Russie. Ils [ses amis] ont su, qu'il existait même une lettre originale aux archives, écrite par un certain Montagut. [...] Elle avait été adressée à Constantinople à la maison Florinville et ensuite envoyée au Comité ». Ce courrier évoque une opération d'envergure pour saboter la flotte russe de la Mer Noire, au moyen de cordages souffrés et bitumés, dans laquelle de nombreuses personnes, dont des Russes, sont impliquées. Besnard remarque que Montagut n'a pas part à ce projet qu'il considère comme impossible. Cependant, si ces informations sont justes, elles indiquent que premièrement Montagut a eu des activités de correspondance avec le comité révolutionnaire, et deuxièmement qu'il a entretenu certains rapports avec des opposants du régime russe. Toutefois, elles sont communiquées trop tard pour le procès de Montagut, qui, se trouvant en Sibérie, n'a pas à répondre de ces nouvelles accusations.

Il ne faut pas conclure d'après ces trois dossiers qu'il n'y a pas eu d'autres espions Français en Russie entre 1792 et 1799. Le gouvernement révolutionnaire français a suivi de très près les moindres événements poli-

(63) Antraigues, Emmanuel-Louis-Henri de Launay, comte d' (1753-1812), homme politique et agent secret. Il émigre en mars 1790 en Suisse puis à Venise. À propos du rôle du comte d'Antraigues dans la diplomatie des émigrés et surtout dans l’espionnage, voir Léonce Pingaud, Un Agent Secret sous La Révolution et l'Empire : Le Comte d'Antraigues, Paris, Plon, 1894. 
tiques en Russie, car toute guerre de l'Empire avec ses voisins ou tout secours apporté aux émigrés, pouvait avoir des conséquences sur la situation en France. D'anciens informateurs de la communauté française ont continué à communiquer des renseignements, mais de nouveaux agents ont aussi été envoyés.

Les émigrés nobles aident particulièrement le pouvoir russe à les débusquer, à la fois parce qu'ils sont leurs ennemis, mais aussi pour entrer dans les bonnes grâces du gouvernement russe. Ainsi le comte d'Antraigues, grâce à son réseau d'informateurs au Ministère à Paris, communique aussi en 1794 des informations concernant un autre espion français en Russie, qui signe Pietro Alado ${ }^{64}$. D'après ses renseignements, il s'agit d'un négociant de Saint-Pétersbourg, qui envoie ses lettres à Copenhague, d'où elles sont réexpédiées à Paris. Cependant si les marchands sont étroitement surveillés, aucune arrestation ne fait suite à ces révélations. De même, en mai 1798, un aide de camp du prince de Condé dénonce un espion nommé Chaidel ${ }^{165}$, âgé d'environ 65 ans, longtemps établi à Lyon dans le commerce. « En 1796 il est parti pour Pétersbourg chargé d'une mission révolutionnaire on en ignore les détails on sait seulement qu'il y a quatre mois on avait à Lyon la certitude qu'il était encore à Pétersbourg et qu'il y avait des succès ». Il se cache évidemment sous un autre nom, et malgré un signalement très précis, il ne peut être identifié. Cependant, si certains agents ont réussi à passer à travers les mailles serrées de la chancellerie secrète, ils n'ont vraisemblablement pas pu jouer un rôle important. En effet la grande désorganisation du pouvoir en France, les fréquents changements d'orientation du régime, les nombreuses difficultés intérieures comme extérieures, n'ont pas permis la constitution d'un réseau d'espions efficace. Tout au plus, la France a pu obtenir quelques renseignements, mais aucun agent ne semble avoir eu une quelconque influence sur le cours de la politique russe. En revanche, dans les années qui suivent immédiatement, Talleyrand semble remettre en ordre un service d'agents efficaces à Saint-Pétersbourg, et, par l'intermédiaire de deux femmes, il réussit à partir de 1800 à rapprocher le Premier Consul et Paul I“r, ainsi qu'à desservir les princes français en exil, ce qui va bien au-delà de simples activités d'information ${ }^{6 / .}$.

(64) RGADA, fonds 7/2, $\pi^{\circ} 2817$. op. cit. Dans la même lettre que celle où il dénonce Montagut.

(65) RGADA, fonds $7 / 2, n^{\circ} 3138$. "Sur la recherche de l'étranger Chaidel, suspecté d'espionnage révolutionnaire. 1798 ".

(66) Olivier Bt.ANC, Les Espions de la Révolution et de l'Empire, Paris, Perrin, 1995. Le chapitre consacré à la Russic n'évoque pas d'agents secrets avant 1800 . $\mathrm{M}^{\mathrm{mc}}$ Chevalier profite de ses succès, en particulicr dans le lit du favori Ivan Kutajzov et peut-être même de l'empereur Paul I't pour faire circuler des informations. Voir aussi à son sujet RGADA, fonds $7 / 2, n^{\circ} 3144$ « Sur les acteurs français Chevalier et sa femme, accusé d'être révolutionnaires. 1798 ». Quant à $\mathrm{M}^{\mathrm{mr}}$ de Bonneuil, elle use de ses relations particulières avec le ministre Rostopchin pour influencer avec succès la politique de l'Empire, contribuant notamment à l'expulsion de Louis XVIII de Mitau. 
La période de 1792 à 1799 correspond pour la communauté française en Russie, à des années de suspicion, de constante surveillance, voire de vexations. L'oukase du 8 février 1793 met un terme aux relations avec la France révolutionnaire, et oblige tous ceux qui désirent rester en Russie à accepter ses conditions. Il couvre d'un voile sombre la vie jusqu'alors plutôt brillante et libre des Français de Russie, qui doivent dorénavant se faire plus discrets. Les différentes affaires qui concernent des Français aux idées plus ou moins révolutionnaires, ou qui ont commis des étourderies ou de petites falsifications, montrent toute la sévérité de la législation. Il ne serait cependant pas juste de qualifier ces mesures d'arbitraires, car elles ne font qu'appliquer une loi connue de tous. En outre il faut aussi souligner que les peines les plus fréquentes sont l'expulsion de l'Empire, parfois la déportation en Sibérie. L'emprisonnement est extrêmement rare, et réservé aux cas particuliers d'espionnage. La torture et les peines corporelles ne sont jamais appliquées. Même si la justice impériale n'est pas toujours clémente, elle tend à être humaine.

De ce bilan, il ne semble pas non plus qu'il soit possible de constater un changement entre les règnes des deux souverains. Si les affaires sous Catherine II sont moins nombreuses, elles ont aussi beaucoup plus d'ampleur. C'est l'impératrice qui fait arrêter les premiers penseurs, c'est elle qui publie l'oukase contre les Français et demande leur serment de fidélité, c'est elle qui sévit contre les trois espions supposés ou avérés. Paul I ${ }^{\mathrm{e}}$, qui est souvent qualifié de despote aux mesures arbitraires, ne fait que continuer à appliquer la législation de sa mère, à la lettre il est vrai, et avec une police bien plus efficace, ce qui entraîne une inflation des affaires, en particulier concernant des Russes. Cependant il faut reconnaître qu'il atténue aussi les mesures économiques contre la France.

Enfin il faut s'interroger sur l'utilité de telles mesures. Y a-t-il eu en Russie un risque réel de contagion révolutionnaire ? Premièrement il ne semble pas que le gouvernement français, occupé de problèmes intérieurs et des conflits avec ses voisins, ait tenté de faire naître en Russie le moindre soutien, et les espions ont tout au plus eu un rôle informatif et non subversif. Deuxièmement, de la part de la communauté française, il est aussi peu probable qu'elle ait cherché à développer la Révolution en Russie, car si certains Français ont des idées libérales, ils sont redevables à l'Empire de leur sort et savent qu'ils ont beaucoup à perdre. En outre ils ont peu d'influence à la cour, pas vraiment de pouvoir ni administratif, ni militaire, et peu de relations avec la population. Troisièmement le peuple russe dans son ensemble n'est pas sensible aux idées démocratiques et peu enclin à suivre le modèle français. Mais en revanche, il est tout à fait capable de 
conduire une révolte comme celle de Pugacev ${ }^{67}$ qui a réellement mis en danger Catherine II, ou encore d'approuver une révolution de palais, comme celle qui a mis l'impératrice elle-même sur son trône, ou celle qui marque la fin du règne de Paul I ${ }^{\text {er }}$ par son assassinat en 1801. C'est pour ces dernières raisons, que les souverains russes se sentent menacés. Ils réagissent en condamnant aussi bien les Français révolutionnaires de l'Empire, que des écrivains russes trop critiques comme Radichev ou Novikov. Toutes ces réactions partent d'une seule et même hantise : la peur d'être détrôné. Quant à l'efficacité de telles mesures, il est fort possible qu'elles aient freiné la diffusion des idées libérales en Russie et maintenu le peuple dans la crainte du pouvoir.

Enfin, il faut reconnaître que l'attitude de l'autocratie russe à l'égard des réfugiés français, même contre-révolutionnaires, n'a en rien été originale. En Angleterre, en Espagne et dans les États pontificaux, les émigrés français et les prêtres réfractaires, ont été l'objet de la même méfiance répressive.

\section{Julie OlLIVIER}

doctorante en histoire moderne

Résidence le beau Chêne appt. A23

164, rue des Chênes

45160 Olivet

julie.ollivier@yahoo.fr

(67) Pugacev, Emel'jan Ivanovic (1740 ou 1742-1775) : sc faisant passer pour le tsar Pierre III, époux de Catherine II assassiné au profit de l'impératrice, il prend la tête d'une révolte populaire de grande ampleur en 1773, arrêtée avec difficultés en 1775. 